Full Paper

\title{
Porphyrin Substituent Regiochemistry, Conformation and Packing - The Case of 5,10-Diphenylporphyrin
}

Mathias O. Senge, ${ }^{\mathrm{a}}$ Katja Dahms, ${ }^{\mathrm{a}}$ Hans-Jürgen Holdt, ${ }^{\mathrm{b}}$ and Alexandra Kelling ${ }^{\mathrm{b}}$

a School of Chemistry, SFI Tetrapyrrole Laboratory, Trinity Biomedical Sciences

Institute, 152-160 Pearse Street, Trinity College Dublin, The University of Dublin, Dublin 2, Ireland

${ }^{\mathrm{b}}$ Institut für Chemie, Universität Potsdam, Karl-Liebknecht-Straße. 24-25, 14476 Golm, Germany

Reprint requests to Prof. Dr. M. O. Senge. Fax: \#353-1-896-8537. E-mail: sengem@tcd.ie

5,10-Disubstituted porphyrins are more recent additions to the family of meso-substituted porphyrins. A crystallographic comparison of 5,10-diphenylporphyrin with the regioisomeric 5,15-disubstituted system reveals striking differences in their conformation. In the free base porphyrins the former uses mainly out-of-plane distortion to alleviate steric strain while in-plane core elongation predominates in the latter. In contrast, the structure of the $\mathrm{Cu}(\mathrm{II})$ complex is planar and forms strong $\pi-\pi$ aggregates with very small lateral shifts. Macroscopically, the packing is similar to that of porphyrin sponges of the 5,10,15,20-tetraphenylporphyrin type. 
Key words: Porphyrins, Conformational Analysis, Tetrapyrroles, Crystal Structure

\section{Introduction}

Porphyrins are conformationally flexible and their macrocycle conformation can be modulated significantly via metal and substituent effects [1, 2]. At the same time, core and peripheral substituents influence the packing of the molecules, e. g., with regard to the formation of $\pi-\pi$-aggregates [3-5]. With thousands of porphyrin crystal structures available by now a detailed picture has emerged for the structural chemistry of these macrocycles. However, most of these refer to symmetric porphyrins with four or more peripheral substituents or complex structures. Some fundamental topics, such as subtle conformational effects in regioisomeric porphyrins received less attention.

For example, the relative impact of meso 5,10- versus 5,15-disubstitution has only been investigated in so-called 'highly substituted' porphyrins, $i$. e. those with $\beta$ - and meso substituents $\mathbf{1}[2,6]$. In these the conformational effects of the meso substituents are very pronounced, due to the possibility of peri-interactions of the meso residue with the flanking $\beta$-substituents [7]. Less is known about the influence of "few" mesosubstituents. For meso-disubstituted porphyrins (such as $\mathbf{2}$ or 3 ) only the crystal chemistry of the easily accessible $5,15-\mathrm{A}_{2}$ type systems has been studied in some detail [8] and compared with related systems of $\mathbf{1}$ [9]. Up to now, no structure of a 5,10-

disubstituted porphyrin had been reported. Syntheses thereof have become available only in the last decade [10-12]. 


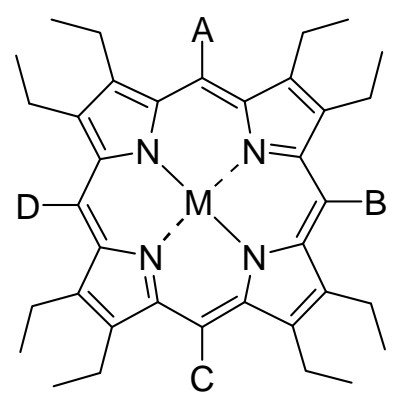

1

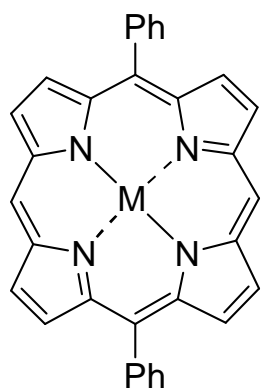

2

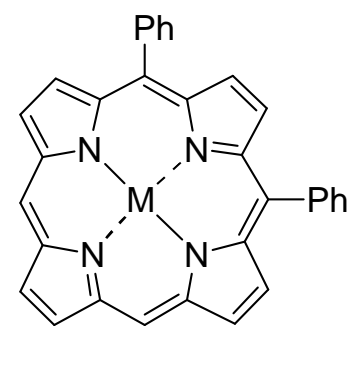

3

Here we report the first crystal structures of 5,10-disubstituted porphyrins without any $\beta$-substituents. The most widely studied porphyrin is $5,10,15,20$ tetraphenylporphyrin which has served as a workhorse in porphyrin structural chemistry [4]. Due to the multitude of meso-phenylporphyrin structures available for comparison, we focused our initial attention on 5,10-diphenyl porphyrin [10, 11].

\section{Results and Discussion}

The free base porphyrin crystallizes in the monoclinic space group $P 2_{1} / \mathrm{c}$ with one molecule in the asymmetric unit (Fig. 1). The macrocycle has a moderate degree of nonplanarity. This is evidenced by an average displacement of the 24 macrocycle atoms from their least-squares-plane $(\Delta 24)$ of $0.102 \AA$. Similar to the situation in other mesoarylporphyrins, the phenyl residues are tilted against the macrocycle plane by $60.5^{\circ}$ and $59.9^{\circ}$ for the phenyl rings at C5 and C10, respectively. The molecular packing is 
characterized by a herringbone arrangement with the phenyl groups positioned between the porphyrin rings. The $4 \mathrm{~N}$-planes of individual porphyrin 'chains' are coplanar and there is no significant $\pi-\pi$-interaction. Two $4 \mathrm{~N}$-planes of neighboring porphyrin systems are skewed against each other by $48.6^{\circ}$ (Fig. 2). This is similar to the situation described by Bond et al. for related 5,15-disubstituted porphyrins [8]. A change to a more mesogenic structure, e. g., in 5,15-bis(4-pentoxyphenyl)porphyrin, results in the formation of parallel layers of molecules in the crystal [13].

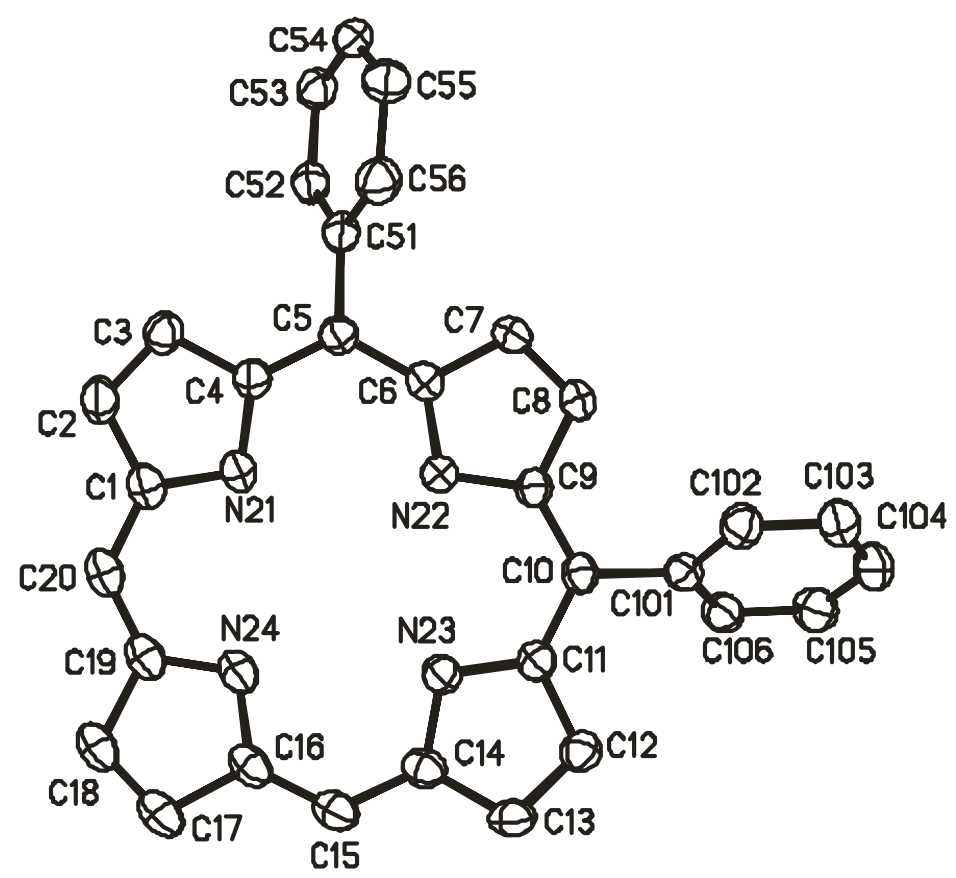

Fig. 1. View of the molecular structure of 5,10-diphenylporphyrin $\left(\mathbf{H}_{2} \mathbf{3}\right)$ in the crystal. Displacement ellipsoids are drawn at the 50 \% probability level. Hydrogen atoms have been omitted for clarity. 

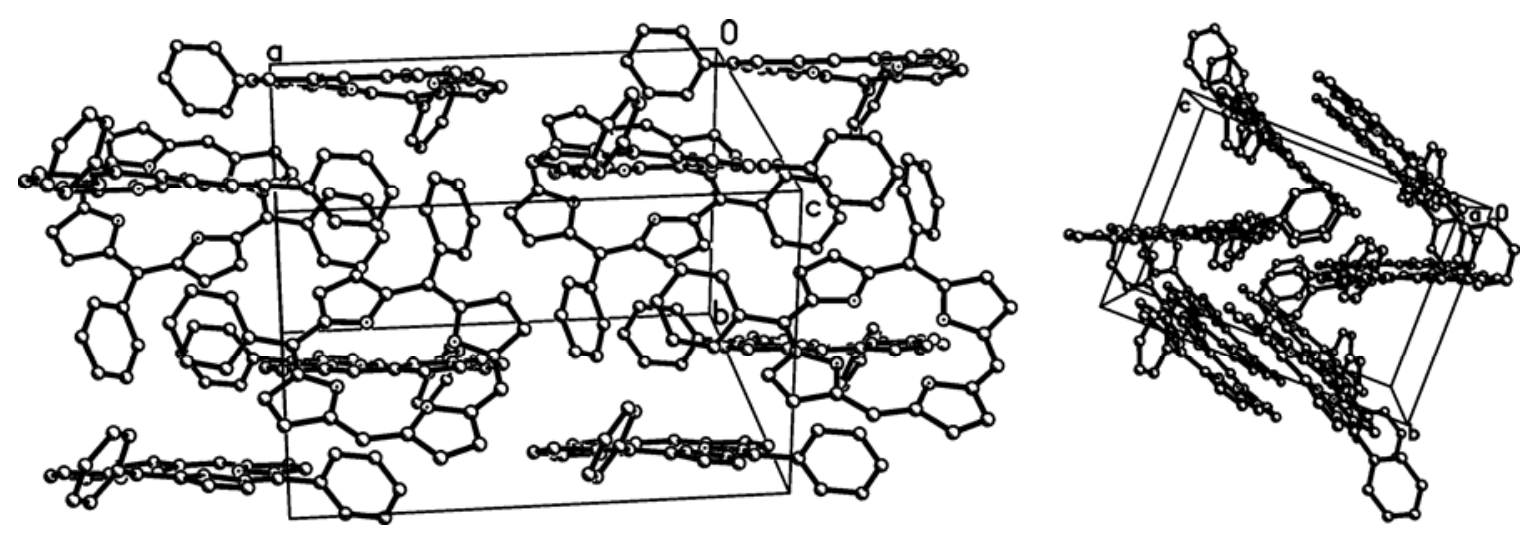

Fig. 2. Two different views of the molecular packing of 5,10-diphenylporphyrin $\left(\mathbf{H}_{2} \mathbf{2}\right)$ in the crystal. Hydrogen atoms have been omitted for clarity.

The most interesting differences between the free base 5,15- and 5,10-diphenylated porphyrins relates to the core conformation and the orientation of the phenyl rings. 5,15Disubstituted free base porphyrins are characterized by a core elongation, i.e. a stretching of the macrocycle along the 5,15-axis [9]. This is clearly evidenced by the difference in $\mathrm{N}^{\cdots} \mathrm{N}$ separations perpendicular and parallel to the substituted 5,15-axis in $\mathbf{H}_{\mathbf{2}} \mathbf{2}$ (Table 1) and 5,15-bis(4-pentoxyphenyl)porphyrin (2.804 versus $3.033 \AA$, [13]). This is clearly not the case in the 5,10-diphenylated porphyrin $\mathbf{H}_{2} 3$, i. e. this porphyrin has a more symmetric core conformation. Likewise, the typical displacement of the meso phenyl residues out of the macrocycle plane (mostly anti) in 5,15-disubstituted porphyrins is absent in the 5,10-derivative. Thus, the 5,10-disubstituted porphyrin resembles more the 5,10,15,20-tetrasubstituted systems [1].

Table 1. Geometrical parameters for the core conformation in diphenylporphyrins ( $\AA$ ). 


\begin{tabular}{llll}
\hline Porphyrin & $\mathbf{H}_{2} 2[5,15]$ & $\mathbf{H}_{2} 2 \cdot \mathrm{CH}_{2} \mathrm{Cl}_{2}[5,15]$ & $\mathbf{H}_{2} 3 \cdot[5,10]$ \\
\hline $\mathrm{N} 21 . . \mathrm{N} 22$ & $2.757(1)$ & $2.772(1)$ & $2.929(2)$ \\
$\mathrm{N} 22 \ldots \mathrm{N} 23$ & $3.065(1)$ & $3.031(1)$ & $2.867(2)$ \\
$\mathrm{N} 23 . . \mathrm{N} 24$ & $2.750(1)$ & $2.775(2)$ & $2.946(2)$ \\
$\mathrm{N} 24 . . \mathrm{N} 21$ & $3.055(1)$ & $3.023(1)$ & $2.890(2)$ \\
\hline
\end{tabular}

At a first glance this is surprising. If potential peri-interactions in 5,15-disubstituted porphyrins are minimized via core elongation and phenyl displacements, then one could expect similar but stronger effects in 5,10-disubsituted systems. Here the two areas of potential peri-interactions are located within one quadrant and not in two halves of the macrocycle. This can only be answered by a more detailed conformational analysis and requires a look at the individual distortion modes. Thus a normal-coordinate structural decomposition (NSD) analysis was performed (Fig. 3). NSD classifies the distortions in terms of equivalent displacements along the normal coordinates and illustrates the mix of distortion modes present in porphyrins $[14,15]$. 


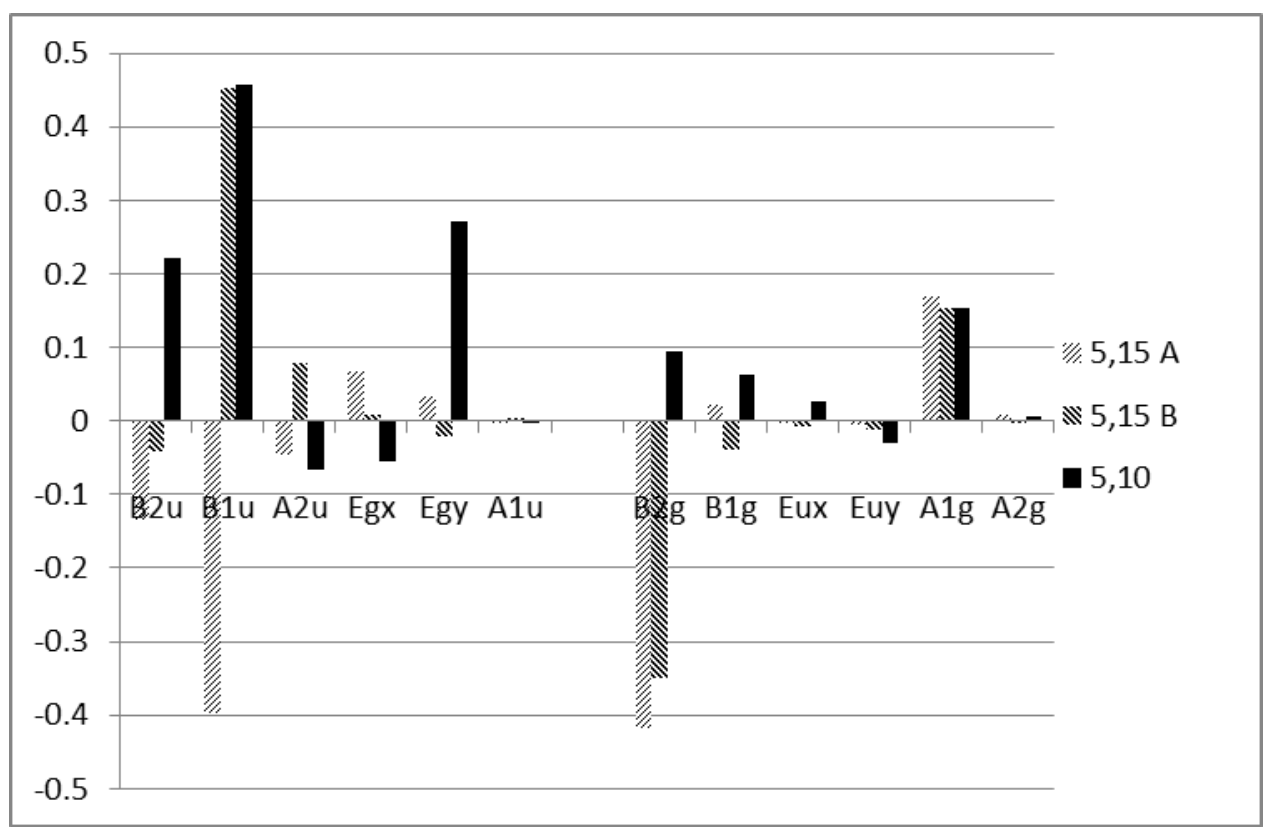

Fig. 3. Normal-coordinate structural decomposition analysis of free base diphenylporphyrins. 5,15A $=\mathbf{H}_{2} 2,5,15 \mathrm{~B}=\mathbf{H}_{2} 2 \cdot \mathrm{CH}_{2} \mathrm{Cl}_{2}, 5,10=\mathbf{H}_{2} 3$.

The 5,15-diphenylporphyrin is characterized by large B1u and B2g distortions and a significant contribution from A1g. This is indicative of out-of-plane ruffling, and in-plane macrocycle m-stretching, and breathing. B1u and A1g contributions are present to a similar extent in the 5,10-regioisomer, while the stretching contribution is much smaller. While only a minor saddle (B2u) distortion is present in the 5,15 derivative, this is noticeably more pronounced in the $\mathbf{H}_{2} 3$. The main conformational difference between the two regioisomers is found in the contribution from $\mathrm{E}_{\mathrm{g}}(\mathrm{x})$. This is indicative of a wave distortion and is only present in the 5,10-isomer. Thus, this free base macrocycle 'relaxes' more through out-of-plane than in-plane distortion.

The copper(II) complex of $\mathbf{H}_{2}$ 3was prepared by metallation with $\mathrm{Cu}(\mathrm{OAc})_{2}$ and is much less distorted than the free base (Fig. 4). Its $\Delta 24$ is $0.0187 \AA$, and the two phenyl 
rings form dihedral angles of $65.9^{\circ}$ and $70.7^{\circ}$ for $5_{\mathrm{Ph}}$ and $10_{\mathrm{Ph}}$, respectively. There is no evidence for core elongation as the two $\mathrm{N}^{\cdots \cdots} \mathrm{N}$ separations are very similar. Likewise, the phenyl rings are not skewed against the porphyrin plane with the phenyl-ipso carbon atoms being in the $4 \mathrm{~N}$-plane. NSD analysis has confirmed the absence of macrocycle distortion. The largest component identified was $0.062 \AA$ for the B2u distortion mode. Thus, $\mathbf{C u ( I I ) 3}$ is a planar porphyrin.

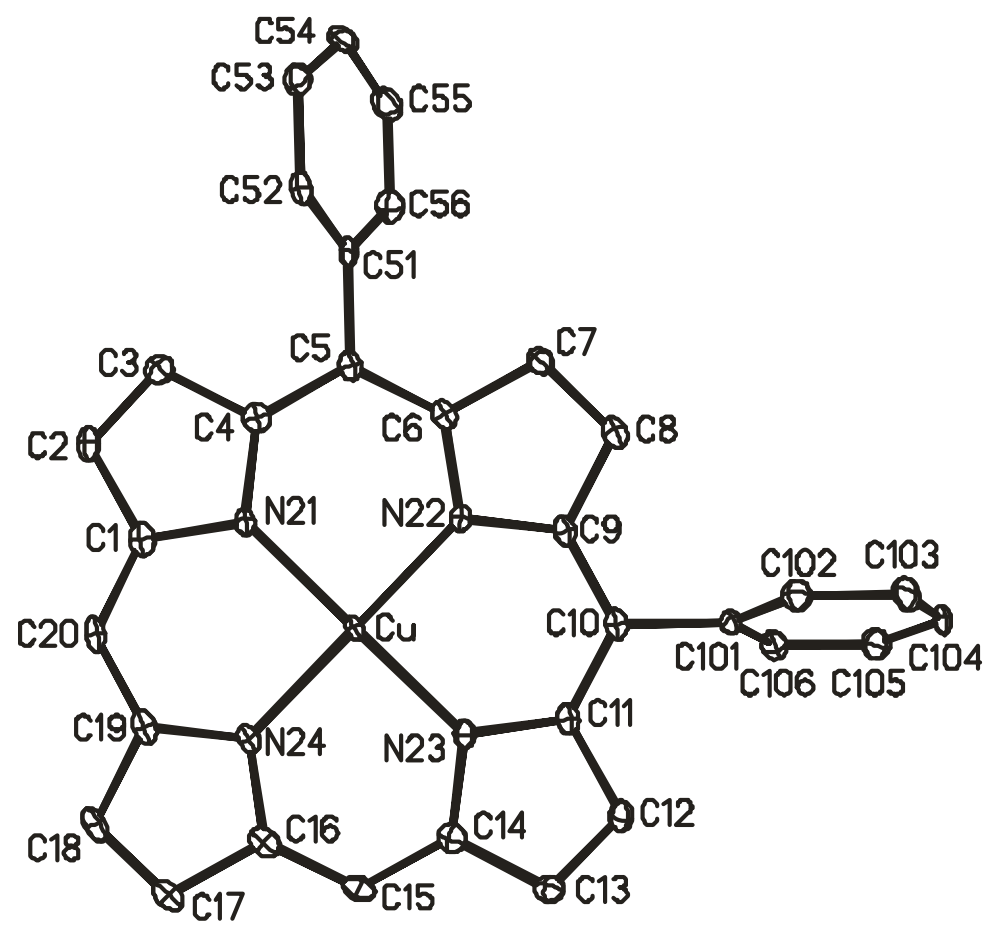

Fig. 4. View of the molecular structure of (5,10-diphenylporphyrinato)copper(II)

(Cu(II)3) in the crystal. Displacement ellipsoids are drawn at the $50 \%$ probability level. Hydrogen atoms have been omitted for clarity.

More interesting is the packing of the molecules $\mathbf{C u}(\mathrm{II}) \mathbf{2}$ (Fig. 5). The compound crystallized as the hexane solvate in the triclinic space group $P \overline{1}$. The asymmetric unit contains the porphyrin and half of the $n$-hexane of solvation. At a rough glance the crystal 
structure looks like that of many tetraphenylporphyrin derivatives (Fig. 5, left). The porphyrin molecules are stacked on top of each other and the space between neighboring porphyrin stacks is filled with $n$-hexane molecules. This is reminiscent of the tetraphenylporphyrin 'sponges' so elegantly described by Strouse and coworkers [16]. Here pairs of 5,10-diphenylporphyrin molecules act as slightly oblong framework units with four phenyl rings pointing outwards.

The impact of the packing becomes evident in a side view of the porphyrin stacks. The molecules are arranged in a head-to-tail (anti-parallel) orientation of the intramolecular dipole moments (resulting from the 5,10-disubstitution pattern). This arrangement was first proposed by Abraham et al. [3], and has since been found in many unsymmetrically substituted porphyrins $[4,5]$.
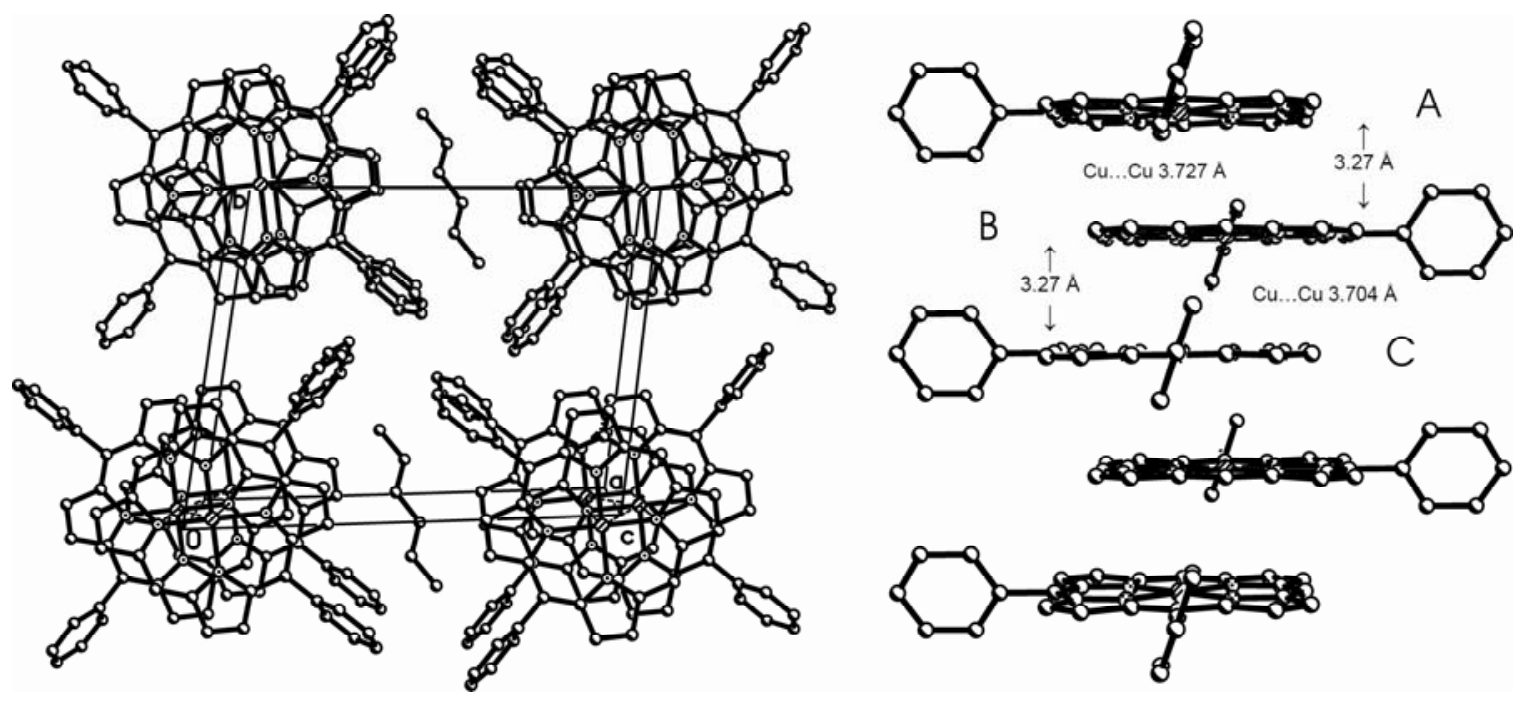

Fig. 5. Two different views of the molecular packing of $(5,10-$

diphenylporphyrinato)copper(II) in the crystal. Hydrogen atoms have been omitted for clarity. 
The orientation of the two phenyl groups in neighboring porphyrins away from each other allows a closer approach of the porphyrin $\pi$-systems. The interplanar separations of neighboring porphyrin rings are $3.27 \AA$, while the $\mathrm{Cu}{ }^{\cdots}{ }^{\prime} \mathrm{Cu}$ separations (Ct-Ct) are 3.727 and $3.704 \AA$ between molecules A and B and B and C in Fig. 4 (right). The relevant slip angles (S. A.) are $151.4^{\circ}$ and $151.9^{\circ}$, respectively. According to Scheidt and Lee [4] this results in a lateral shift $[\mathrm{L} . \mathrm{S} .=\sin (\mathrm{S}$. A. $) \times \mathrm{Ct}-\mathrm{Ct}]$ of the metal centers against each other of 1.784 and $1.746 \AA$, respectively. Thus, this porphyrin belongs to the 'group S', indicative of strong $\pi-\pi$-interactions.

Clearly, the different arrangement of the meso substituents has an impact on the conformation of the free base porphyrins and on the packing arrangement. This provides further information on the structural variability of the various members of the $A_{x}$ - and ABCD- porphyrin family [17]. It also indicates the possibility that the 5,10-disubstituted porphyrins, with appropriate functional groups, might give rise to unique packing arrangements in the context of crystal engineering [18].

\section{Experimental}

The compounds were prepared as described earlier [12].

\section{X-Ray structure determinations}

Growth and handling of crystals followed the concept developed by Hope [19]. The intensities were corrected for Lorentz, polarization and absorption effects. Nonhydrogen atoms were refined with anisotropic displacement parameters, and hydrogen atoms were placed into geometrically calculated positions and refined using a riding model. The 
structures were solved with Direct Methods or Patterson synthesis using the SHELXTL PLUS program system and refined against $\left|F^{2}\right|$ with the program SHELXL using all data [20].

Crystal data $\mathbf{H}_{2}$ 3: Crystallized from $\mathrm{CHCl}_{3} / \mathrm{CH}_{3} \mathrm{OH}$ as red-brown plates. $\mathrm{C}_{32} \mathrm{H}_{22} \mathrm{~N}_{4}$, $M=462.54$, monoclinic, space group $P 2{ }_{1} / c, a=15.886(2), b=10.2906(8), c=14.586(2)$ $\AA, \beta=90.318(9)^{\circ}, V=2384.4(4) \AA^{3}, Z=4, T=200 \mathrm{~K}, \mu\left(\mathrm{MoK}_{\alpha}\right)=0.1 \mathrm{~cm}^{-1}, 7282$ reflections measured, 3978 unique reflections measured $\left(R_{\text {int }}=0.0558\right), 326$ parameters, 2740 reflections with $I>2.0 \sigma(I)$, refinement against $\left|\mathrm{F}^{2}\right|, R 1(I>2.0 \sigma(I))=0.0370, w R 2$ (all data) $=0.0861, S=0.908, \rho_{\max }=0.435$. Refinement: The pyrrole hydrogen atoms were disordered over all four positions and refined with 50 \% occupancy each.

Crystal data $\mathbf{C u ( I I ) 3 : ~ C r y s t a l l i z e d ~ f r o m ~} \mathrm{CHCl}_{3} / n$-hexane as red cubes. $\mathrm{C}_{32} \mathrm{H}_{20} \mathrm{~N}_{4} \mathrm{Cu} 0.5 \mathrm{C}_{6} \mathrm{H}_{14}, M=567.18$, triclinic, space group $P \overline{1}, a=6.5444(3), b=$ 12.6076(5), $c=16.3804(7) \AA, \alpha=80.625(8)^{\circ}, \beta=79.278(7)^{\circ}, \gamma=79.688(7)^{\circ}, V=$ 1294.7(1) $\AA^{3}, Z=2, T=90 \mathrm{~K}, \mu\left(\mathrm{MoK}_{\alpha}\right)=0.9 \mathrm{~cm}^{-1}, 20153$ reflections measured, 7121 unique reflections measured $\left(R_{\text {int }}=0.0388\right)$, 362 parameters, 5746 reflections with $I>2.0$ $\sigma(I)$, refinement against $\left|\mathrm{F}^{2}\right|, R 1(I>2.0 \sigma(I))=0.0488, w R 2$ (all data) $=0.1138, S=$ 1.081, $\rho_{\max }=0.972$. Refinement: The hexane molecule of solvation was refined with 50 \% occupancy. Due to low diffraction high angle reflections were omitted from the refinement.

CCDC $1023282 \quad\left(\mathbf{H}_{2} \mathbf{3}\right)$ and 1023283 (Cu(II)3) contain the supplementary crystallographic data for this paper. These data can be obtained free of charge from The Cambridge Crystallographic Data Centre via www.ccdc.cam.ac.uk/data_request/cif. 


\section{Acknowledgement}

This work was supported by grants from Science Foundation Ireland (SFI P.I. 09/IN.1/B2650 and IvP 13/IA/1894 SFI).

[1] J. L. Hoard, Ann. N.Y. Acad. Sci. 1973, 206, 18-31.

[2] M. O. Senge, Chem. Commun. 2006, 243-256.

[3] R. J. Abraham, B. Evans, K. M. Smith, Tetrahedron 1978, 34, 1213-1220.

[4] W. R. Scheidt, Y. J. Lee, Struct. Bond. (Berlin) 1987, 64, 1-73.

[5] M. O. Senge, C. W. Eigenbrot, T. D. Brennan, J. Shusta, W. R. Scheidt, Inorg. Chem. 1993, 32, 3134-3142.

[6] J.-H. Fuhrhop, L. Witte, W. S. Sheldrick, Liebigs Ann. Chem. 1976, 1537-1559.

[7] M. B. Hursthouse, S. Neidle, J. Chem. Soc., Chem. Commun. 1972, 449-450.

[8] A. D. Bond, N. Feeder, J. E. Redman, S. J. Teat, J. K. M. Sanders, Crystal Growth Des. 2002, 2, 27-39.

[9] M. O. Senge, C. J. Medforth, T. P. Forsyth, D. A. Lee, M. M. Olmstead, W. Jentzen, R. K. Pandey, J. A. Shelnutt, K. M. Smith, Inorg. Chem. 1997, 36, 1149_ 1163.

[10] R. P. Brinas, C. Brückner, Tetrahedron 2002, 58, 4375-4381.

[11] S. Hatscher, M. O. Senge, Tetrahedron Lett. 2003, 44, 157-160.

[12] C. Ryppa, M. O. Senge, S. S. Hatscher, E. Kleinpeter, P. Wacker, U. Schilde, A. Wiehe, Chem. Eur. J. 2005, 11, 3427-3442.

[13] M. O. Senge, Acta Crystallogr. 2013, E69, o1048. 
[14] a) W. Jentzen, X.-Z. Song, J. A. Shelnutt, J. Phys. Chem. B 1997, 101, 16841699.

[15] Normal StRuctural DECOMPOSITION ENGINE Version 3.0; http://jasheln.unm.edu/jasheln/content/nsd/NSDengine/start.htm, $\quad$ accessed 09/07/2014.

[16] M. P. Byrn, C. J. Curtis, Y. Hsiou, S. I. Khan, P. A. Sawin, S. K. Tendick, A. Terzis, C. E. Strouse, J. Am. Chem. Soc. 1993, 115, 9480-9497.

[17] M. O. Senge, Chem. Commun. 2011, 47, 1943-1960.

[18] I. Goldberg, Chem. Commun. 2005, 1243-1254.

[19] H. Hope, Prog. Inorg. Chem. 1994, 41, 1-19.

[20] G. M. Sheldrick, Acta Crystallogr. 2008, A64, 112-122. 
Content section suggestions (3 different ones, whichever you like best):
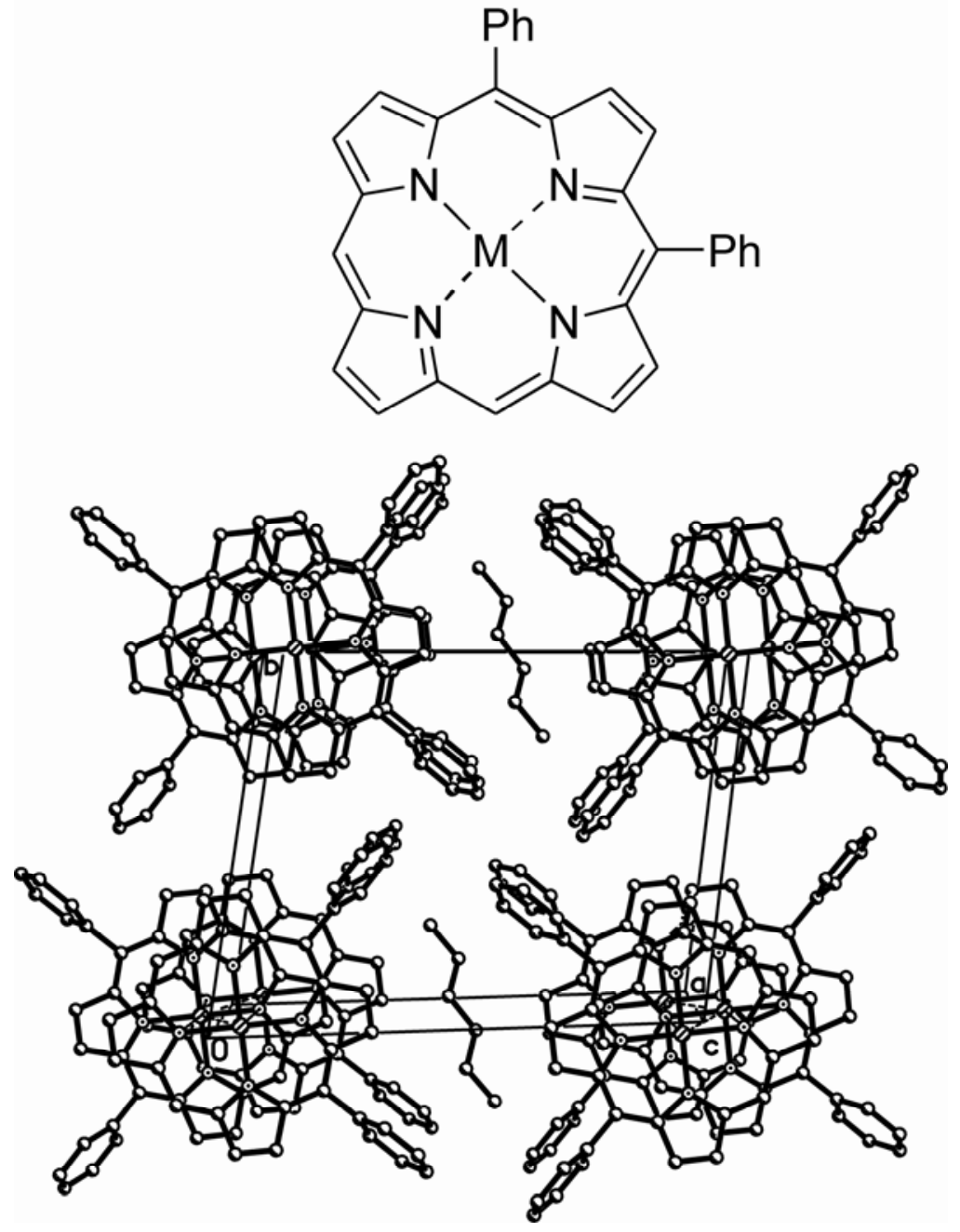


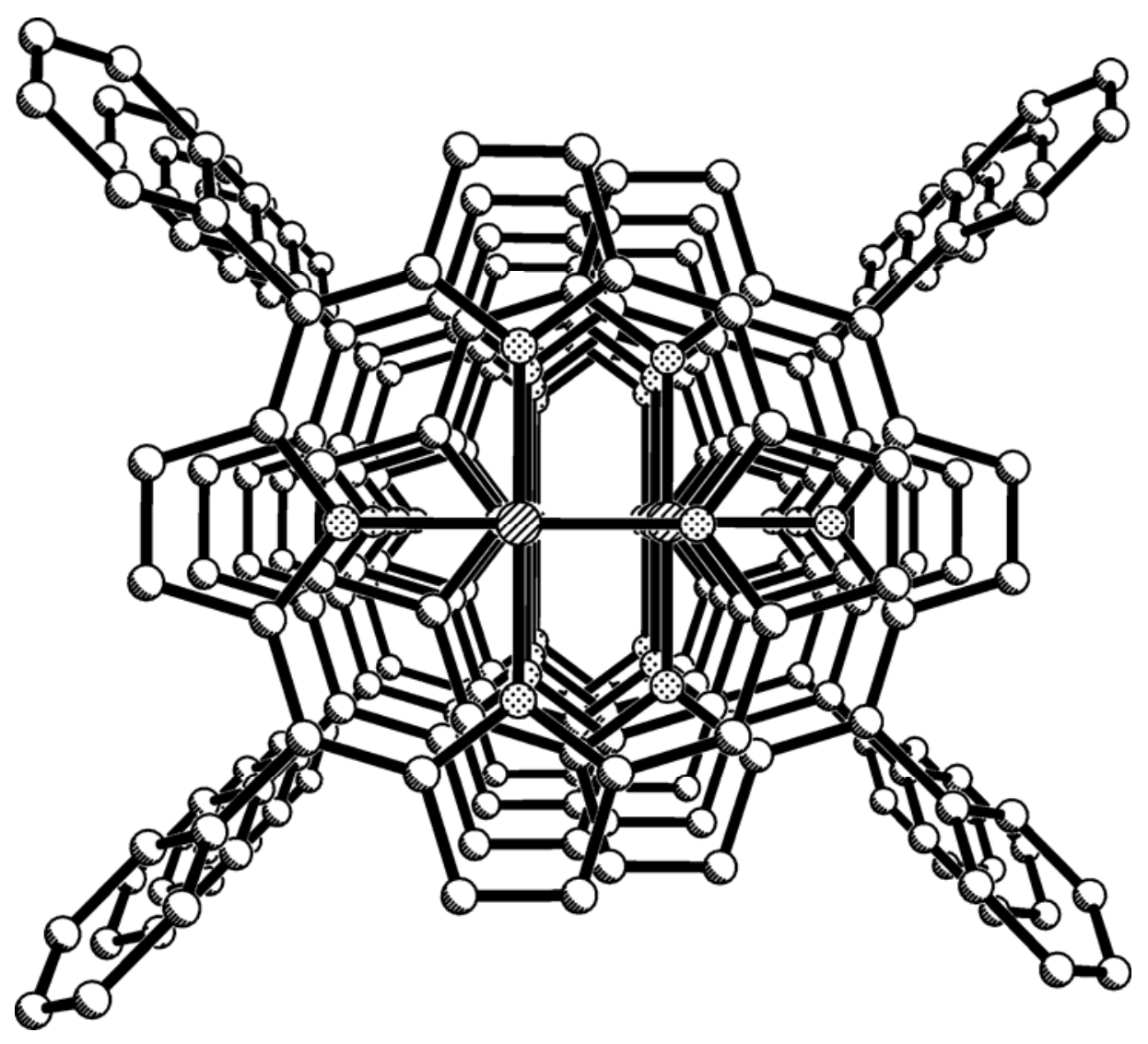


16

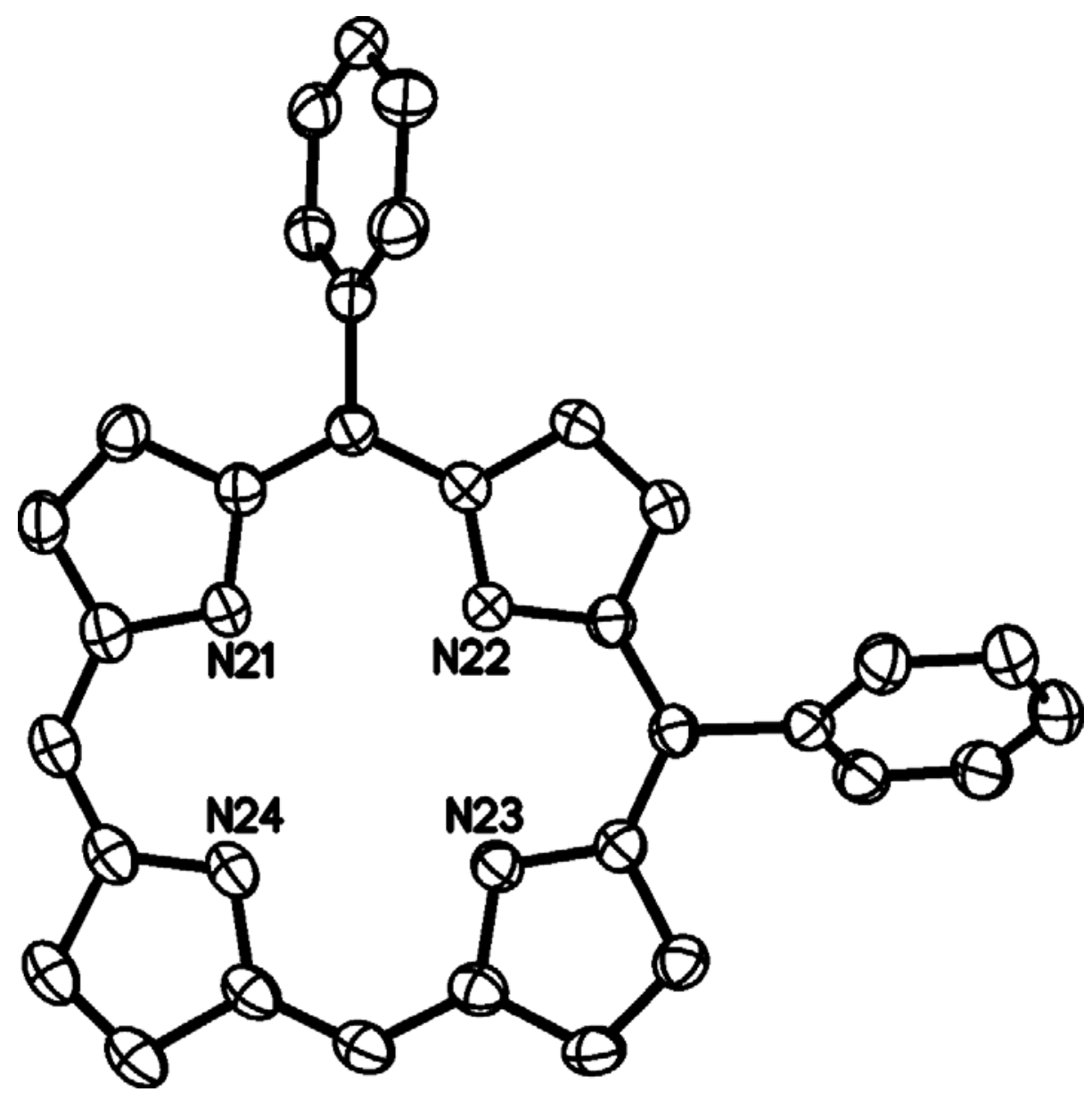

16 